Conclusion From our study was found that there is a directly proportional relationship between hypocomplementemia and the severity of haematological involvement in SLE patients.

The more severe it is the haematological involvement, the more affected seem to be the complement serum levels.

\section{PS7:149 COLD COMPRESS FROM CASSAVA AS A NOVEL THERAPY TO PREVENT EXACERBATIONS AND IMPROVE QUALITY OF LIFE OF LUPUS PATIENTS WITH STRESS}

ESD Sari. Universitas Brawijaya, Malang, Indonesia

\subsection{6/lupus-2018-abstract.192}

Cassava is one of Indonesia's natural materials that can be utilised as a basic ingredient of cold compress. New effect of cold compress founded to decrease the stress responses of Lupus patients. Purpose: to know the effects of cold compress from cassava to reduce stress responses, decrease exacerbations, and improve quality of life of patients with Lupus.

Methods 126 young adult Lupus patients with similar in sex, ethnicity, education status, and active disease activity (SLEDAI score >3) measured their stress responses and quality of life using Lupus Quality of Life Questionnaire (Lupus-QoL) (pretest). Stress responses measured include physical responses \{blood pressure, respiratory, headache scale, and insomnia using Insomnia Rating Scale (IRS), cognitive responses using Cognitive Symptoms Inventory (CSI), and emotional responses using Depression Anxiety and Stress Scale (DASS)\}. Lupus patients with positive stress responses were given therapy of cold compress from cassava (17-24C) in forehead area for $20 \mathrm{~min}$ before bedtime for one week. Patients with cold allergies, open wounds in the compressed area, circulatory disorders, and Raynaud's syndrome were excluded. After one week of therapy, the patients $(n=114)$ measured SLEDAI score, stress responses, and quality of life (posttest).

Results 62\% had elevated blood pressure; 68\% had respiratory enhancement; $72 \%$ had moderate-to-severe headache; $68 \%$ had insomnia; 56\% increased CSI score; and 62\% had mildto-severe stress level. Cold compress therapy have significant effects in decreasing stress responses including respiratory, headache, insomnia, cognitive impairment, and stress levels $(\mathrm{p}=0.08, \mathrm{p}=0.01, \mathrm{p}=0.00, \mathrm{p}=0.02$, and $\mathrm{p}=0.00$ respectively). The SLEDAI score decreased 32\% $(\mathrm{p}=0.04)$ and the LupusQoL increased 27\% $(p=0.03)$. Suspected, local effects of vasoconstriction, decrease capillary permeability, and decrease temperature of prefrontal cortex in the brain by cold compress can decrease vasodilatation when headache occur and induce patients to sleep early. At bedtime, norepinephrine levels will decrease so the cognitive and emotional stress responses can be repaired. No side effects were found.

Conclusions This is a preliminary evidence to support hypothesis of development of cold compress from cassava as stress therapy in lupus that can be used to prevent exacerbations and improve the quality of life of Lupus patients.

\section{Poster session 8: Registries and cohorts}

\section{PS8:150 MYCOBACTERIAL INFECTION IN SYSTEMIC LUPUS ERYTHEMATOSUS: CLINICAL SIGNIFICANCE AND ASSOCIATED FACTORS. DATA FROM THE REGISTRY OF PATIENTS WITH SLE OF THE SPANISH SOCIETY OF RHEUMATOLOGY (RELESSER)}

${ }^{1} \mathrm{~A}$ Lois Iglesias, ${ }^{2} \mathrm{~V}$ del Campo-Pérez, ${ }^{3} \mid$ Rúa-Figueroa, ${ }^{2} \mathrm{C}$ Mouriño, ${ }^{4} \mathrm{FJ}$ lópez-tongo, ${ }^{5} \mathrm{M}$ Galindo, ${ }^{6} \mathrm{M}$ Calvo-Alén, ${ }^{8} \mathrm{~A}$ Olivé, ${ }^{7} \mathrm{E}$ Uriarte, ${ }^{9} \mathrm{~A}$ Fdez-Nebro, ${ }^{10} \mathrm{JA}$ Bernal, ${ }^{3} \mathrm{C}$ Erausquin, ${ }^{11} \mathrm{E}$ Tomero, ${ }^{12} \mathrm{~L}$ Horcada, ${ }^{1} \mathrm{M}$ Freire, ${ }^{13} \mathrm{C}$ Montilla, ${ }^{14} \mathrm{~A}$ Sánchez, ${ }^{15} \mathrm{~A}$ Boteanu, ${ }^{16} \mathrm{E}$ Diez, ${ }^{17} \mathrm{~J}$ Narváez, ${ }^{18} \mathrm{~V}$ Martínez-Taboada, ${ }^{19} \mathrm{~L}$ Silva, ${ }^{20} \mathrm{JL}$ Andreu, ${ }^{2} \mathrm{R}$ Melero, ${ }^{2} \mathrm{JM}$ Pego-

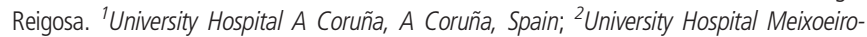
EOXI Vigo, Spain; ${ }^{3}$ University Hospital Dr Negrin, Gran Canaria, Spain; ${ }^{4}$ University Hospital Gregorio Marañon, Madrid, Spain; ${ }^{5}$ University Hospital 12 de Octubre, Madrid, Spain: ${ }^{6}$ University Hospital Alava, Spain; ${ }^{7}$ University Hospital Donosti, San Sebastian, Spain; ${ }^{8}$ University Hospital Germans Trias I Pujol, Barcelona, Spain; ${ }^{9}$ University Hospital Carlos Haya, Málaga, Spain; ${ }^{10}$ University Hospital Alicante, Alicante, Spain; ${ }^{11}$ University Hospital La Princesa, Madrid, Spain; ${ }^{12}$ University Hospital Navarra, Pamplona, Spain; ${ }^{13}$ University Hospital Salamanca, Salamanca, Spain; ${ }^{14}$ University Hospital Principe de Asturias, Madrid, Spain; ${ }^{15}$ University Hospital Ramón y Cajal, Madrid, Spain; ${ }^{16}$ University Hospital León, León, Spain; ${ }^{17}$ University Hospital Bellvitge, Bellvitge, Spain; ${ }^{18}$ University Hospital Marqués de Valdecilla, Santander, Spain; ${ }^{19}$ University Hospital Ferrol, Ferrol, Spain; ${ }^{20}$ University Hospital Puerta de Hierro, Madrid, Spain

10.1136/lupus-2018-abstract.193

The aim of this work is to study the prevalence of mycobacterial infection (M.I.), the associated factors and their clinical significance in patients included in a large SLE cohort.

Methods Retrospective descriptive study of RELESSER patients with a history of M.I. and analysis of the factors associated with the infection of this aetiology.

Results In RELESSER 3,658 SLE patients were included. 90\% women, mean age of 32.9 years. 93\% Caucasians. The mean follow-up time ( \pm S.D.) was 120.2 ( \pm 87.6$)$ months. 705 (19.3\%) patients had at least a serious infection, 1227 serious infections occurred. M.I. were diagnosed in 42 patients $(1.2 \%$ of all RELESSER patients, $3.4 \%$ of all serious infections), $85.7 \%$ women. The incidence rate of mycobacterial infection was 1 per 1000 patients/year (95\% CI: 0.7 to 1.4 ).

M.I. presentation was pulmonary in 18 (42.9\%) patients and extrapulmonary in 24 (57.1\%)patients:joints in $8(19.0 \%)$ patients, soft tissue in $6(14.3 \%)$ and other sites in 10 (23.8\%). The extrapulmonary form was associated with the use of immunosuppressants: $84.6 \%$ of the 13 patients treated with immunosuppressive drugs versus $44.4 \%$ of the 27 patients without $(p=0.01)$. We did not observe this association with the use of corticosteroids.

To study the factors associated with mycobacterial infection, we performed a bivariate analysis including the variables associated with severe infection identified in RELESSER (age, sex, ethnicity, use of corticosteroids, immunosuppressants, antimalarials, previous admission by SLE activity, use of rituximab, use of anti-TNF, Katz severity index, SDI damage index, SLEDAI activity index and Charlson comorbidity index). There is a statistically significant association with previous admission by SLE activity (RR: $2.9,95-95 \%$ CI: 1.3 to $6.2, p=0.007$ ), renal impairment (RR:2.0, 95\% CI: 1,1 to 3,7, p=0,04), the Katz 
score (RR: 2.1, 95\% CI:1.1-4.0,p=0.04) and the Charlson index (RR: 2.5 ; 95\% CI: 1.3 to $4.8, \mathrm{p}=0.009$ ). The accumulated damage (SDI $>0)$ was closely associated with significance: RR: 2.0 ; 95\% CI: 1.0 to $4.0, p=0.07$. The use of immunosuppressants was associated with a significant increase in the risk of mycobacterial infection: RR: 4.3 ; 95\% CI: 2.2 to 8.3 , $\mathrm{p}=0.31$.

Two patients (4.8\%) died (1respiratory and 1extrapulmonary). The mean survival after diagnosis in these cases was 21 days.

Conclusion M.I. in RELESSER affects $1.15 \%$ of patients. Its incidence rate is 1 per 1000 patients/year (95\% CI: 0.7 to 1.4). Extrapulmonary localization affects more than half of the patients and is associated with the use of immunosuppressants. Previous admission by SLE activity, renal involvement, severity of SLE, and increased number of associated comorbidities are factors associated with the existence of mycobacterial infection.

\section{PS8:151 HEMOPHAGOCYTIC SYNDROME IN PATIENTS FROM SLE REGISTRY FROM THE SPANISH SOCIETY OF RHEUMATOLOGY (RELESSER)}

${ }^{1} \mathrm{~A}$ Lois Iglesias, ${ }^{1} \mathrm{FJ}$ de Toro-Santos, ${ }^{2} \mathrm{~A}$ Zea, ${ }^{3} \mathrm{M}$ Galindo, ${ }^{4} \mathrm{E}$ Uriarte, ${ }^{5}$ Rua-Figueroa, ${ }^{6} J \mathrm{M}$ Pego-Reigos. ' University Hospital A Coruña, A Coruña, Spain; ${ }^{2}$ University Hospital Ramón y Cajal, Madrid, Spain; ${ }^{3}$ University Hospital 12 de Octubre, Madrid, Spain; ${ }^{4}$ University Hospital Donosti, San Sebastián, Spain; ${ }^{5}$ University Hospital Dr Negrin, Gran Canaria, Spain; ${ }^{6}$ University Hospital Meixoeiro-EOXI Vigo, Vigo, Spain

\subsection{6/lupus-2018-abstract.194}

Background SLE in our area presents hematologic manifestations in approximately $70 \%$ of cases. Some of them are very rare, there are no large series whose analysis could provide relevant information.
Objectives To study the characteristics of patients with Hemophagocytic Syndrome (HS) in a large sample of SLE patients. Methods SLE patients from RELESSER database were studied. We analysed the SLE manifestations present at 12domains (mucocutaneous, renal, musculoskeletal, constitutional, hematologic, vascular, cardiac, respiratory, neuropsychiatric, gastrointestinal, ophthalmic and serological) before, during and after HS diagnosis and until the last available assessment. We studied activity (SELENA- SLEDAI) and damage (SLICC/ACR DI) indices in each of those moments. We evaluated the treatment received, HS recurrences and the deaths by this entity.

Results 3656 patients from 45Rheumatology Units across Spain were studied.7patients with SLE and HS were identified. $71.4 \%$ were women, with a mean age $( \pm S D)$ at the diagnosis of $\mathrm{SH}$ of $35.1( \pm 17.1)$ years. In 5 of the 7 cases the HS occurred $115.5( \pm 162.9$ months after the diagnosis of SLE. In the remaining 2 cases the diagnosis of both entities was simultaneous. The main triggers of HS were infections, followed by SLE activity flares. At the time of HS diagnosis, they had high SLE activity with a mean SLEDAI score of $13.1( \pm 11.3)$ and $1.4( \pm 2.3)$ SDI scores. Clinically, $100 \%$ of the patients presented fever and alterations of the liver profile, $85.8 \%$ cytopenias and $71.5 \%$ dermatological manifestations. Respiratory manifestations and hemolytic anaemia were present in $57.2 \%$ of the cases. Lymph nodes and coagulopathy in $42.9 \%$. Hepatomegaly was detected in $28.6 \%$, as well as neuropsychiatric, digestive and renal manifestations. Splenomegaly was detected in $14.3 \%$. The mean haemoglobin level was $8.6( \pm 1.1) \mathrm{g} / \mathrm{dl}$, platelets $85585( \pm 83,390)$, ferritin $7410( \pm 6,470) \mathrm{n} / \mathrm{ml}$ and triglycerides $404.7( \pm 235.6) \mathrm{mg} / \mathrm{dl}$.All patients underwent a bone marrow study.All patients were admitted. They required an average of $2.2( \pm 1.5)$ treatment lines, using $2.8( \pm 1.7)$ drugs. One patient died during the HS episode and another 2 patients had 2 and 3 recurrences respectively.

\section{Abstract PS8:151 Table 1}

\begin{tabular}{|c|c|c|c|c|c|c|c|}
\hline & \begin{tabular}{|l|} 
Patient 1 \\
\end{tabular} & Patient 2 & Patient 3 & Patient 4 & Patient 5 & Patient 6 & Patient 7 \\
\hline $\begin{array}{c}\text { Number of organ } \\
\text { systems affected } \\
\text { by SLE before HS } \\
\text { diagnosis }\end{array}$ & 9 & 4 & 5 & 5 & 6 & $\begin{array}{c}\text { Simultaneous diagnosis of } \\
\text { SLE and SH }\end{array}$ & $\begin{array}{c}\text { Simultaneous diagnosis of } \\
\text { SLE and SH }\end{array}$ \\
\hline $\begin{array}{c}\text { Number of organ } \\
\text { systems affected } \\
\text { by SLE at HS } \\
\text { diagnosis }\end{array}$ & 4 & 1 & 2 & 4 & 2 & 4 & 3 \\
\hline $\begin{array}{l}\text { Number of organ } \\
\text { systems affected } \\
\text { by SLE until last } \\
\text { assessment }\end{array}$ & Died & 2 & 2 & Follow-up lost & 1 & 5 & 1 \\
\hline $\begin{array}{c}\text { SLEDAI//SLICC- } \\
\text { ACR DI at HS } \\
\text { diagnosis }\end{array}$ & $4 / / 6$ & $4 / / 0$ & $5 / / 0$ & $29 / / 3$ & $4 / / 1$ & $25 / / 0$ & $21 / / 0$ \\
\hline \begin{tabular}{|c|} 
SLEDAI//SLICC- \\
ACR DI 1 year \\
after HS \\
\end{tabular} & * & $0 / / 0$ & $0 / / 0$ & * & $2 / / 1$ & $0 / / 0$ & $2 / / 13$ \\
\hline $\begin{array}{c}\text { SLEDAI//SLICC ACR } \\
\text { DI at last } \\
\text { assessment } \\
\end{array}$ & * & $0 / / 0$ & $0 / / 0$ & * & $0 / / 1$ & $2 / 10$ & $2 / / 13$ \\
\hline $\begin{array}{c}\text { Number of } \\
\text { treatment lines }\end{array}$ & 1 & 0 & 3 & 2 & 2 & 4 & 3 \\
\hline Number & 2 & & 5 & 3 & 2 & 4 & 4 \\
\hline $\begin{array}{l}\text { Treatments } \\
\text { administered }\end{array}$ & $\begin{array}{l}\mathrm{GC} \text { and } \\
\text { CSA }\end{array}$ & 0 & $\begin{array}{c}\text { GCs, etoposide, } \\
\text { iv Ig, CsA, } \\
\text { platelets, red } \\
\text { cells }\end{array}$ & GC, CYP and iv Ig & $\begin{array}{c}\text { Amphotericin B, } \\
\text { miltefosine }\end{array}$ & GC, iv Ig, CsA, MM & GC, CS A, anakinra and CYP \\
\hline Relapses & 0 & 2 & 0 & 3 & 0 & 0 & 0 \\
\hline Deaths & Yes & No & No & No & No & No & No \\
\hline $\begin{array}{l}\text { Follow-up time } \\
\text { (months) }\end{array}$ & Died & 45 & 80 & Follow-up lost & Unknown & 26 & 24 \\
\hline
\end{tabular}

